\title{
CDOM retrieval using measurements of downwelling irradiance
}

\author{
K. Linnemann*a, P. Gege ${ }^{b}$, S. Rößler ${ }^{a}$, T. Schneider ${ }^{a}$ and A. Melzer ${ }^{a}$ \\ ${ }^{\mathrm{a}}$ Technische Universität München, Limnologische Station Iffeldorf, Am Hofmark 1-3, 82393 \\ Iffeldorf, Germany; ${ }^{b}$ Deutsches Zentrum für Luft- und Raumfahrt (DLR), Institut für Methodik der \\ Fernerkundung, Oberpfaffenhofen, 82234 Wessling, Germany
}

\begin{abstract}
As it can strongly influence the availability of light and thus primary production, coloured dissolved organic matter (CDOM) affects the function of lake ecosystems. Therefore reliable methods are required for the monitoring of CDOM concentration. A new method using downwelling irradiance was tested for applicability in four selected lakes of the Bavarian Osterseen Lake District, which consists of 19 naturally connected freshwater lakes of different trophic level. The method separates between the direct and diffuse part of the incident light in order to handle the strong variability of the underwater light field. It is implemented in the software WASI, which is capable to retrieve water constituents by inverse modeling. During field campaigns downwelling irradiance measurements using RAMSES sensors were made in different depths. Simultaneously, water samples were taken in three depths $(0.5 \mathrm{~m}, 2 \mathrm{~m}$ and Secchi disk depth), from which the absorption coefficient of CDOM, $a_{Y}$, was derived in the range from 190 to $900 \mathrm{~nm}$ using photometric absorption measurements. Concentration (defined as $a_{Y}$ at $440 \mathrm{~nm}$ ) ranged from 0.33 to $1.55 \mathrm{~m}^{-1}$ with a mean of $0.71 \mathrm{~m}^{-1}$ $\pm 0.04 \mathrm{~m}^{-1}$, the spectral slope at $440 \mathrm{~nm}$ from 0.0120 to $0.0184 \mathrm{~nm}^{-1}$ with a mean of $0.0145 \pm 0.0008 \mathrm{~nm}^{-1}$. These laboratory measurements from water samples were compared to CDOM concentration obtained by inverse modeling of downwelling irradiance measurements using WASI. For sensor depths lower than 1 to $1.5 \mathrm{~m}$ large uncertainties were observed. The measurements in $2 \mathrm{~m}$ depth and at Secchi disk depth yielded good correlation between water sample and WASI derived data $\left(\mathrm{R}^{2}=0.87\right)$ with a mean standard deviation of $0.06 \mathrm{~m}^{-1}$ for the determined CDOM concentrations. This new method is an alternative to laboratory analysis of water samples from in situ measurements of CDOM concentration.
\end{abstract}

Keywords: inland waters, monitoring, water constituents, CDOM, downwelling irradiance, RAMSES sensors, inverse modeling, WASI

\section{INTRODUCTION}

Coloured dissolved organic matter (CDOM) influences the structure and function of aquatic ecosystems ${ }^{1}$ like freshwater lakes. Comprising the chromophoric fraction of the dissolved organic carbon (DOC), CDOM is a strong absorber of the incident radiation especially in the UV and the blue spectral region. Therefore optical properties of CDOM contribute to the inherent optical properties (IOPs) of lake ecosystems ${ }^{2}$ and significantly affect the availability of light and thus transparency ${ }^{3}$. At high concentration CDOM negatively influences underwater photosynthetic active radiation (PAR, 400 $-700 \mathrm{~nm}$ ) and light can get the limiting factor for photoautotrophic algae $e^{4-6}$. On the other hand, CDOM is required as an important carbon source for heterotrophic bacteria in freshwater lakes ${ }^{7}$ and plays a central role in the mobility of nutrients and different organic and inorganic toxins. As major parts of CDOM enter lake ecosystems via input of riverine water and surface water runoff, monitoring of CDOM concentration and type can give important information about changes in the surrounding catchment area ${ }^{8}$. Like all aquatic ecosystems, freshwater lakes are exposed to numerous environmental changes mostly of anthropogenic nature, changes that could also alter natural carbon fluxes and consequently structure and function of freshwater lakes ${ }^{1}$. For instance, increasing CDOM concentration was observed in rivers draining peatlands in the northern hemisphere during the last decades ${ }^{9,10}$. The driving factor is still under discussion $^{11}$. The hypotheses include rising temperature as consequence of climatic change, changing river discharge, and induced changes in the landscape water balance. Methods for the retrieval of CDOM are therefore of great interest to predict future changes in carbon cycle and possible changes in water quality ${ }^{11}$.

*kathrin.linnemann@outlook.com

Remote Sensing of the Ocean, Sea Ice, Coastal Waters, and Large Water Regions 2013,

edited by Charles R. Bostater, Jr., Stelios P. Mertikas, Xavier Neyt, Proc. of SPIE Vol. 8888 88880I · C 2013 SPIE · CCC code: 0277-786X/13/\$18 - doi: 10.1117/12.2031250 
Hyperspectral in situ radiation measurements could be a proficient method for spatial CDOM monitoring. Determination of CDOM has been successfully performed by analysis of spaceborne ${ }^{11}$ and airborne ${ }^{12}$ images, but these methods are bound to several limitations. Multispectral spaceborne sensors have only broad spectral bands and data acquisition is restricted to the fixed times of the satellite overpass, whereas hyperspectral airborne sensors offer the required spectral resolution but are too cost intensive for regular observations. In addition, due to clouds and sunglint many images cannot be used. With in situ radiation measurements samples can be taken any time and throughout the water column. The use of reliable bio-optical models for the inversion of radiation measurements offers a much more efficient data analysis than laboratory. Additionally in situ radiation measurement can contribute to interpretation and validation of remote sensing algorithms ${ }^{13}$.

A new method using under water measurements of downwelling irradiance, $E_{d}$, turned out to be an effective method for the determination of sensor depth ${ }^{13}$ and phytoplankton concentration ${ }^{14}$. Treating the direct and diffuse components of $E_{d}$ separately, this new model can correct effects of disturbance from the water surface. Being of great interest for the monitoring of future changes in carbon cycle, the new model is tested for the retrieval of CDOM concentration.

\section{IRRADIANCE MODEL}

The downwelling irradiance in water is rarely used to derive water constituents since the measurements are generally highly variable (Figure 1a). The variability is mainly caused by the water surface ${ }^{15}$. Waves, ripples and foam alter steadily the refraction angle of the incident rays, leading to focusing and defocusing effects ${ }^{16,17}$. The induced changes of intensity are typically in the order of 20 to $40 \%$ in the upper few meters ${ }^{18,19}$, but flashes can be an order of magnitude above average ${ }^{20}$. Because the incident angles are different for the direct ( $E_{d d}$, representing the sun disk) and diffuse $\left(E_{d s}\right.$, representing the sky) irradiance components, the effect of the water surface on the two components is different, i.e. the intensity changes of $E_{d d}$ and $E_{d s}$ are only weakly correlated ${ }^{15}$. Consequently, the spectral shape of $E_{d}$ is fluctuating as well (red curve of Figure 1a) since the spectral shapes of $E_{d d}$ and $E_{d s}$ are different (Figure 1b). A model that can handle this variability of $E_{d}$ intensity and spectral shape was developed recently ${ }^{21,22}$. The concept is summarized below, for details see the cited references.
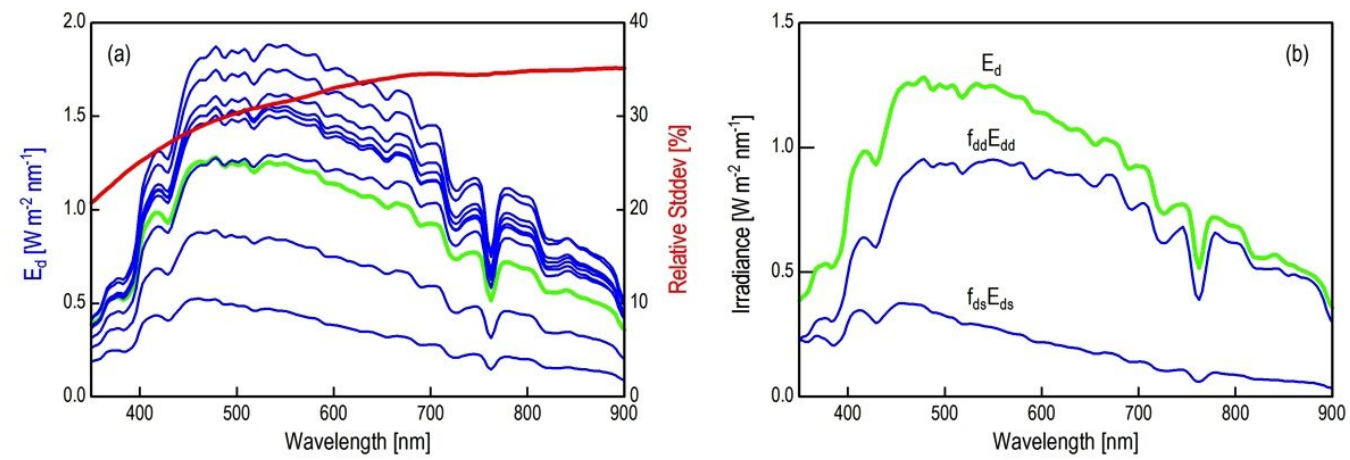

Figure 1. Illustration of downwelling irradiance in water. (a) Short-term variability of $E_{d} .10$ measurements were made within $100 \mathrm{~s}$ just below the water surface. The standard deviation illustrates the associated changes of spectral shape. (b) Differences between the irradiance components. The described model was used to separate the direct $\left(E_{d d}\right)$ and diffuse $\left(E_{d s}\right)$ components for the green marked $E_{d}$ measurement of panel (a). The relative intensities were $f_{d d}=0.97$ and $f_{d s}=0.69$.

The downwelling irradiance at depth $z$ and wavelength $\lambda$ is expressed as a weighted sum of $E_{d d}$ and $E_{d s}$ as follows:

$$
E_{d}(\lambda, z)=f_{d d} E_{d d}(\lambda, z)+f_{d s} E_{d s}(\lambda, z)
$$

The wavelength-independent parameters $f_{d d}$ and $f_{d s}$ describe the intensities of $E_{d d}$ and $E_{d s}$ relative to conditions with a plane water surface. They change from measurement to measurement and are not known a priori. $f$ factors $<1$ correspond to intensity decrease, $f$ factors $>1$ to intensity increase. They can be determined during data analysis if (1) a model for calculating $E_{d d}(\lambda, z)$ and $E_{d s}(\lambda, z)$ for a plane water surface exists, and (2) the dimensionality of the $E_{d}$ measurements is higher than the number of model parameters, i.e. wavelength range, number of channels and signal-to-noise-ratio are sufficiently high. 
A depth-dependent model of $E_{d d}(\lambda, z)$ and $E_{d s}(\lambda, z)$ has been developed by Gege ${ }^{21}$. It approximates the downwelling irradiance components at the water surface (at $z=0$ ) using the model of Gregg and Carder ${ }^{23}$, which was extended concerning spectral range and spectral resolution. Parameters are the Sun zenith angle $\left(\theta_{\text {sun }}\right)$ and the atmospheric properties Angström exponent of aerosols $(\alpha)$, turbidity coefficient $(\beta)$, scale height of ozone $\left(H_{o z}\right)$ and scale height of precipitable water $(W V) . \alpha$ is a measure of the aerosol type; $\beta, H_{o z}$ and $W V$ are measures of concentration. The four atmospheric parameters $\alpha, \beta, H_{o z}$ and $W V$ are usually unknown, but can be estimated by inverse modeling of an abovewater measurement of $E_{d}(\lambda)$.

The downwelling irradiance components at depth $z>0$ are calculated using the Lambert-Beer-Law $E(z)=E(0) \exp [-K z]$. In contrast to the widely used approach of applying the law to $E_{d}$, it is applied here to $E_{d d}$ and $E_{d s}$ separately in order to account for the different path lengths of the rays forming $E_{d d}(z)$ and $E_{d s}(z)$. This separation reduces significantly the model complexity for the attenuation coefficient $K$ and improves accuracy of $E_{d}(z)$ calculation with increasing depth. While $K_{d}$ of the usual approach is an apparent optical property (AOP) with complicated dependency on geometry parameters ${ }^{24}, K_{d d}$ and $K_{d s}$ of the new approach can be expressed as products of $u(\lambda)=b_{b}(\lambda) /\left[a(\lambda)+b_{b}(\lambda)\right]$, which is an inherent optical property (IOP), and path length normalized to $z$. The normalized path length is very close to 1 for $E_{d d}$, and proportional to the cosine of the underwater Sun zenith angle for $E_{d s}{ }^{21}$. The absorption coefficient $a(\lambda)$ and the backscattering coefficient $b_{b}(\lambda)$ are the optical properties of the water and comprise all extractable information about the water constituents. The irradiance model can exploit the information of $a(\lambda)$, but not reliably that of $b_{b}(\lambda)^{14}$. This enables the determination of CDOM, which is a strongly absorbing component.

\section{METHODS}

\subsection{Study site}

The Osterseen Lake District $\left(47^{\circ} 48^{\prime} \mathrm{N}, 11^{\circ} 18^{\prime} \mathrm{E}\right)$ developed after the last glacial epoch in the Alpine foothills in the South of Munich (Bavaria, Germany). Consisting of 19 naturally connected freshwater lakes (Figure 2), the district can be divided into freshwater lakes located in the North, South and East of the district. Resulting from a contamination of the lake supplying groundwater layer due to municipal wastewater and agricultural management of the catchment area the Osterseen Lake District, originally oligotrophic, was exposed to eutrophication. Because of their connection a nutrient gradient from south to north, following the natural incline of the territory, developed over the years. Being of similar age, origin and morphology contemporary with exposure to the same climatic environment, the freshwater lakes only differ in groundwater supply, trophic level and connectivity to surrounding dystrophic bogs as potential CDOM source. Therefore the Osterseen Lake District contains a wide spectrum of different lake types, optimal for comparative limnological studies ${ }^{25}$.

\subsection{Field campaign data}

Water samples were taken from June to September 2012 in a two-weekly pattern at five sampling sites (Figure 2) selected in the Lake Ostersee (OS1, OS2), Lake Eishaussee (ES1), Lake Fohnsee (FS1) and Lake Sengsee (SS1). Regular sampling was performed only in the southern and eastern lakes of the district, since the northern lakes can't be reached by boat directly. To cover also the northern lakes, 14 of them were sampled during a single campaign on August 14, 2012. Due to its size $\left(1,18 \mathrm{~km}^{2}\right)$ two sampling sites were chosen in Lake Ostersee. At each test site and each campaign, three replicates of one litre water were sampled in three depths $(0.5 \mathrm{~m}, 2 \mathrm{~m}$ and Secchi disk depth (SDD)) using a standard water sampler according to Ruttner (Hydro-Bios). If Secchi disk depth was $2 \mathrm{~m}$ or less, the second sample was taken at $1 \mathrm{~m}$ instead of $2 \mathrm{~m}$ water depth. In the laboratory, water samples were filtered using $0.45 \mu \mathrm{m}$ poresize cellulose-acetate filters (Sartorius Stedim Biotech), filled in PE-bottles and stored in a fridge in dark. Further analysis was performed within one month after the campaign. Then samples were analysed for absorption using a CARY double-beam UV-VIS spectrometer (Agilent Technologies) following the method of $\mathrm{Gege}^{26}$. The transmission of each sample was measured twice in quartz cuvettes with 5 and $10 \mathrm{~cm}$ pathlength (Starna Spectrosil Cuvettes 1/Q/50, 1/Q/100) from 190 to $900 \mathrm{~nm}$ at $1 \mathrm{~nm}$ intervals. The absorption spectrum of the sample was determined from the ratio of the two transmission spectra using the Lambert-Beer law. The CDOM absorption spectrum, $a_{Y}(\lambda)$, was calculated by subtracting the same pure water absorption spectrum that is also used in the model. No correction of offset or temperature was performed. Concentration of CDOM is defined as absorption coefficient at $440 \mathrm{~nm}$.

Simultaneously to water sampling, the downwelling irradiance was measured in water using a hyperspectral TRIOS RAMSES ACC-VIS irradiance sensor (wavelength range 320-900 nm, spectral sampling interval $3.3 \mathrm{~nm}$ ), calibrated by 
TRIOS in 2008. A preferable clear sky and a sun elevation of at least $30^{\circ}{ }^{27}$ were chosen for the measurements. Mounted on a metal frame the upward facing sensor was lowered into the water column using a cable winch. As recommended in literature ${ }^{13}$ data collection started with a measurement above water surface $E_{d}(0+)$, followed by a measurement just below water surface $E_{d}(0-)$. Then the sensor was lowered beneath Secchi disk depth and moved upwards in $0.5 \mathrm{~m}$ steps. Measurements were made up to depths of 4.5 meters. The water depth was recorded simultaneously to the $E_{d}$ measurements by a pressure sensor attached to the RAMSES device. For calibration and equidistant resampling in a wavelength grid of 320 to $950 \mathrm{~nm}$ with a spectral resolution of $3.3 \mathrm{~nm}$ the software MSDA_XE 8.5 (TriOS GmbH) was used.

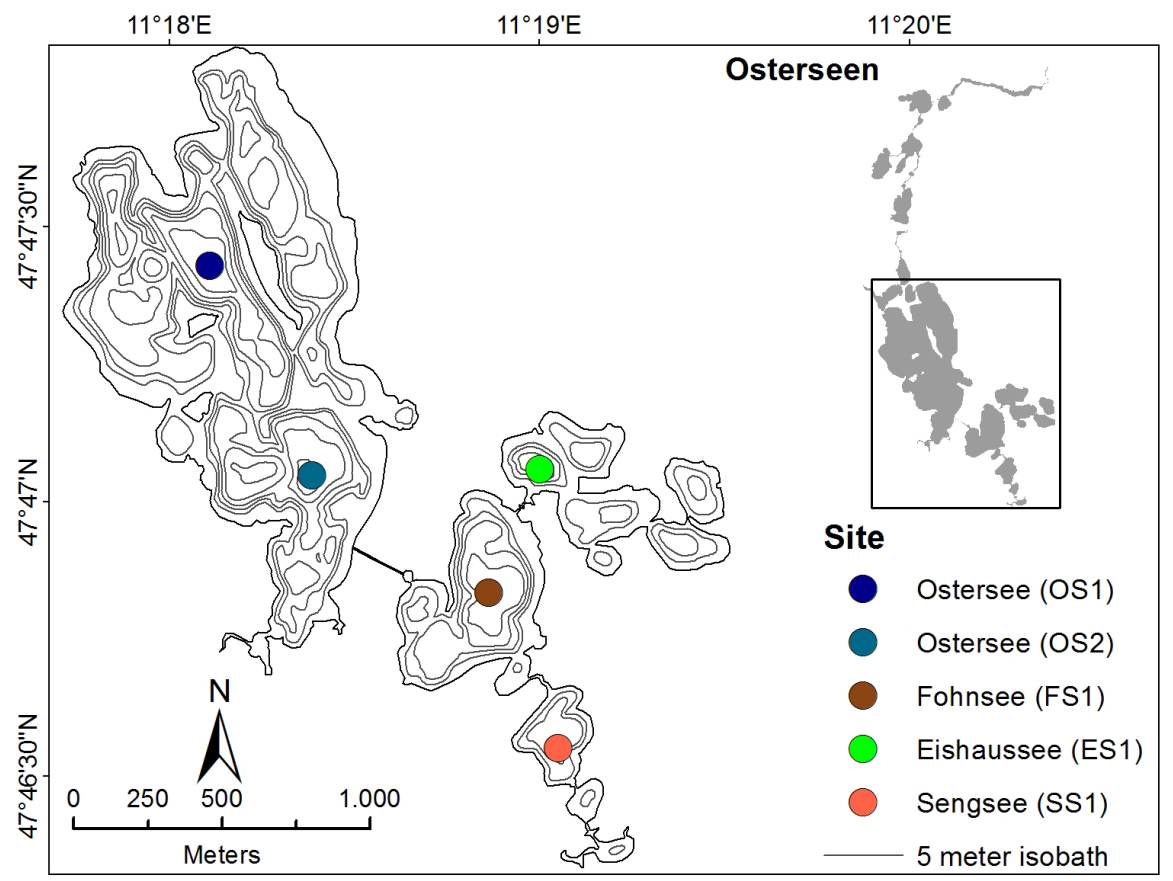

Figure 2. Map of the 19 connected freshwater lakes of the Osterseen Lake District (right) situated in the South of Munich (Bavaria, Germany). Points display the five sampling sites (OS1, OS2, ES1, FS1 and SS1) each at maximum depth in the four selected lakes of the district (left), Lake Ostersee (30.6 and 27.7 m), Lake Eishaussee (20.1 m), Lake Fohnsee (24.6 m) and Lake Sengsee $(15.4 \mathrm{~m})$. Gray lines show the 5 meter isobaths.

\subsection{Data analysis}

The Water Color Simulator WASI was used for data analysis. It allows to simulate and analyse different types of spectral measurements of instruments disposed above the water surface and submerged in the water. Data analysis is done by inverse modeling. The described irradiance model is implemented in WASI version 4. For details of its parameterisation and inverse modeling algorithm see $\mathrm{Gege}^{21}$.

The focus of this study is CDOM retrieval. As described in section 2, CDOM can be determined from irradiance measurements by exploiting the information that is implicitly included in the absorption coefficient of the water body, $a(\lambda)$. WASI treats $a(\lambda)$ as sum of four absorption coefficients that represent pure water, detritus (non-algal particles), phytoplankton, and CDOM. For our dataset, detritus was neglected and phytoplankton was described by three specific absorption coefficients representing the dominant classes of our test sites: diatoms, dinoflagellates, and green algae. CDOM absorption is calculated in WASI as $a_{Y}(\lambda)=Y a_{Y} *(\lambda)$, where $a_{Y} *(\lambda)$ is the specific absorption coefficient, normalized at a reference wavelength $\lambda_{0}$, and $Y=a_{Y}\left(\lambda_{0}\right)$ is the absorption coefficient at $\lambda_{0}$ in units of $\mathrm{m}^{-1} . a_{Y} *(\lambda)$ is a measure of the CDOM type, and $Y$ of CDOM concentration. $a_{Y}{ }^{*}(\lambda)$ is frequently approximated by an exponential function, $a_{Y} *(\lambda)=\exp \left[-S\left(\lambda-\lambda_{0}\right)\right]$. The spectral slope $S$ at $\lambda_{0}=440 \mathrm{~nm}$ is typically in the range between $0.01 \mathrm{~nm}^{-1}$ for humic acid dominated waters and $0.02 \mathrm{~nm}^{-1}$ when fulvic acids prevail. WASI can use either the exponential approximation, or a spectrum $a_{Y}^{*}(\lambda)$ imported from file. 
In this study, the model parameters $C_{i}, X, Y, S, f_{d d}, f_{d s}, \alpha, \beta, H_{o z}, W V$ and $z$ were treated as potential unknowns for individual $E_{d}$ measurements and determined by inverse modeling. The $C_{i}$ are the concentrations of phytoplankton groups $\left(C_{0}\right.$ : weighted sum of the five phytoplankton spectra, $C_{1}$ : cryptophyta "low", $C_{2}$ : cryptophyta "high", $C_{3}$ : diatoms, $C_{4}$ : dinoflagellates, $C_{5}$ : green algae), $X$ is suspended matter concentration, $Y$ and $S$ are the before-mentioned CDOM parameters, $f_{d d}$ and $f_{d s}$ are the relative intensities of direct and diffuse irradiance as described above, $H_{o z}, \alpha, \beta$ and $W V$ are the before-mentioned parameters of the atmosphere, and $z$ is sensor depth.

Inverse modeling was carried out for all $E_{d}$ measurements. The defaults were set to $C_{0}=2 \mathrm{mg} \mathrm{m}^{-3}, C_{i}=0$ for $\mathrm{i}=1 . .5, X=$ $2 \mathrm{~g} \mathrm{~m}^{-3}, Y=0.5 \mathrm{~m}^{-1}, f_{d d}=1, f_{d s}=1, \alpha=1, \beta=0.200, H_{o z}=0.300 \mathrm{~cm}, W V=1.50 \mathrm{~cm}, z=2 \mathrm{~m}$. $S$ was set to $0.0140 \mathrm{~nm}^{-1}$. To test the influence of the initial values on the fit results, different initial values of $Y$ were used $\left(0.002 \mathrm{~m}^{-1}, 1 \mathrm{~m}^{-1}, 5 \mathrm{~m}^{-1}\right.$, $\left.10 \mathrm{~m}^{-1}\right)$. In a next step different $S$ values were set $\left(0.0040 \mathrm{~nm}^{-1}, 0.0250 \mathrm{~nm}^{-1}\right), S$ was set as fit parameter with an initial value of $0.0140 \mathrm{~nm}^{-1}$, and further the average specific absorption spectrum $a_{Y, O S} *(\lambda)$ of all measurements conducted in the Osterseen Lake District was tested instead of the exponential approximation. The influence of phytoplankton absorption on CDOM retrieval was analyzed by using either $C_{0}$ alone or $C_{3}, C_{4}$ and $C_{5}$ together as fit parameters, with initial values of 1 in each case.

\section{RESULTS}

\subsection{Optical properties of CDOM in the Osterseen Lake District}

A summary of the results from the regular campaigns at the lakes Ostersee, Eishaussee, Fohnsee and Sengsee is presented in Table 1. For the individual laboratory measurements, the concentration of CDOM, $a_{Y}(440)$, ranges from 0.33 to $1.55 \mathrm{~m}^{-1}$ with a mean and standard deviation (SD) of $0.71 \pm 0.04 \mathrm{~m}^{-1}$. The spectral slope, $S$, ranges from 0.0120 to $0.0184 \mathrm{~nm}^{-1}$ with a mean and SD of $0.0145 \pm 0.0008 \mathrm{~nm}^{-1}$.

As can be seen in Table 1, the results for $a_{Y}(440)$ are very similar for the two methods and agree within a SD. The SD is typically in the order of $5 \%$ for the laboratory measurements and $10 \%$ for the $E_{d}$ fits, except for the site SS1, where SD of both methods is increased by a factor of two. The agreement of the results for $S$ is less convenient. The comparably high SD of $S$ derived from $E_{d}$ fits indicates that $S$ cannot be determined accurately by inverse modeling of $E_{d}$ measurements (see section 4.2).

The lakes reveal significant differences both in CDOM concentration and type. In Lake Fohnsee the highest concentrations were observed, in Lake Sengsee the lowest. Lake Ostersee and Lake Eishaussee range in between. The parameter $S$, which is a measure of CDOM type, shows the highest values for Lake Ostersee and the lowest for Lake Eishaussee and Lake Sengsee, while Lake Fohnsee lies in between. The two sampling sites in Lake Ostersee constantly show similar values for $a_{Y}(440)$ and $S$.

Table 1. Summary of $a_{Y}(440)$ and $S$ measurements at the main sampling sites. (a) Results of the laboratory measurements. (b) Results from fitting $E_{d}$ spectra. $N=$ number of measurements (different days, different depths), $N^{\prime}=$ number of single irradiance measurements.

\begin{tabular}{|c|c|c|c|c|c|c|c|c|c|c|c|}
\hline \multirow[b]{2}{*}{ Sampling site } & a) & \multicolumn{2}{|c|}{$a_{Y}(440)\left[\mathrm{m}^{-1}\right]$} & \multicolumn{2}{|c|}{$S\left[\mathrm{~nm}^{-1}\right]$} & \multirow[t]{2}{*}{ (b) } & \multirow[b]{2}{*}{$\mathrm{N}^{\prime}$} & \multicolumn{2}{|c|}{$a_{Y}(440)\left[\mathrm{m}^{-1}\right]$} & \multicolumn{2}{|c|}{$S\left[\mathrm{~nm}^{-1}\right]$} \\
\hline & $\mathrm{N}$ & mean & $\mathrm{SD}$ & mean & SD & & & mean & SD & mean & $\mathrm{SD}$ \\
\hline OS1 & 9 & 0.82 & 0.02 & 0.0156 & 0.0004 & 6 & 120 & 0.73 & 0.06 & 0.0134 & 0.0013 \\
\hline OS2 & 9 & 0.81 & 0.04 & 0.0156 & 0.0001 & 6 & 105 & 0.92 & 0.11 & 0.0137 & 0.0013 \\
\hline ES1 & 15 & 0.62 & 0.04 & 0.1380 & 0.0008 & 9 & 135 & 0.64 & 0.05 & 0.0146 & 0.0012 \\
\hline FS1 & 12 & 1.08 & 0.05 & 0.0145 & 0.0006 & 6 & 105 & 1.08 & 0.10 & 0.0143 & 0.0020 \\
\hline SS1 & 15 & 0.40 & 0.04 & 0.0137 & 0.0011 & 9 & 135 & 0.42 & 0.09 & 0.0132 & 0.0024 \\
\hline
\end{tabular}

To visualize regional and temporal variabilities, the complete laboratory dataset measured at all test sites during all campaigns is illustrated in Figure 3. The earliest campaign from June $19^{\text {th }} 2012$ shows the highest $a_{Y}(440)$ for all sampling sites except Lake Eishaussee. Pronounced fluctuations of concentration during the summer are observed in Lake Ostersee and Lake Fohnsee, while $a_{Y}(440)$ in Lake Eishaussee and Lake Sengsee is more constant during summer. 
Comparing the three sampling depths $(0.5 \mathrm{~m}, 2 \mathrm{~m}$ and Secchi disk depth) no significant differences can be seen for $a_{Y}(440)$. The $a_{Y}(440)$ measurements reveal regional differences, i.e. high CDOM concentration for the northern lakes of the district (except Lake Lustsee), and relatively constant concentrations for the southern and eastern lakes. Looking at the spectral slope, the $S$ values are similar in all lakes of the district, ranging from 0.0130 to $0.0150 \mathrm{~nm}^{-1}$, with one extreme value in Lake Ostersee. A regional trend, as was observed for $a_{Y}(440)$, is not visible in the $S$ data. The average of $S$ is $0.0145 \mathrm{~nm}^{-1}$, the $\mathrm{SD} 0.0008 \mathrm{~nm}^{-1}$, i.e. the relative SD is $5 \%$.
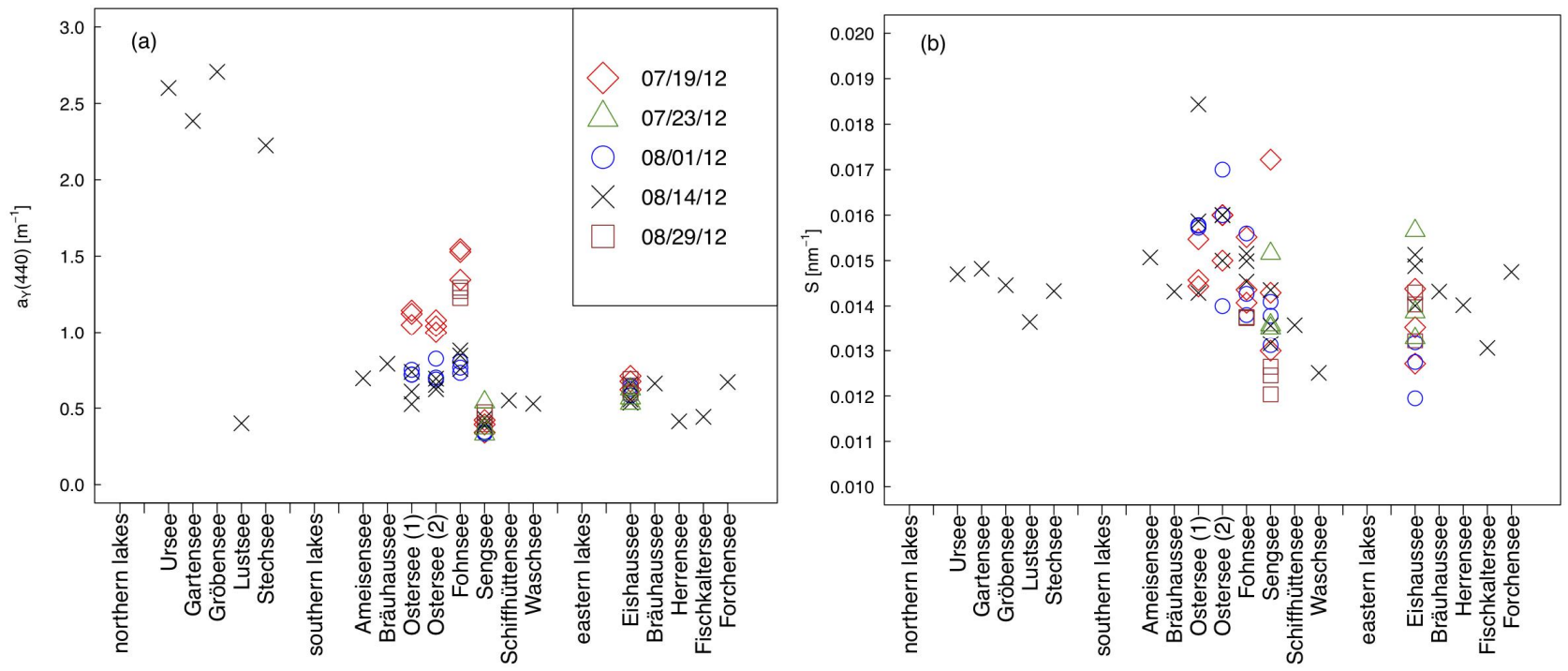

Figure 3. Regional and temporal distribution of CDOM parameters in freshwater lakes of the Osterseen Lake District. The symbols represent the five campaigns carried out during summer 2012. (a) CDOM concentration $a_{Y}(440)$. (b) CDOM spectral slope $S$.

To illustrate differences in specific absorption between the sampling sites, $a_{Y}^{*}(\lambda)$ normalized at the reference wavelength of $\lambda_{0}=440 \mathrm{~nm}$ is presented in Figure 4. Each coefficient represents the average of all samples taken at the specified sampling site. Apparently the shape of the CDOM absorption curve is very similar for all sites. Hence, the average $a_{Y, O S}{ }^{*}(\lambda)$ is taken below as input to WASI representing $a_{Y}{ }^{*}(\lambda)$ during inverse modeling of $E_{d}(\lambda)$ measurements.

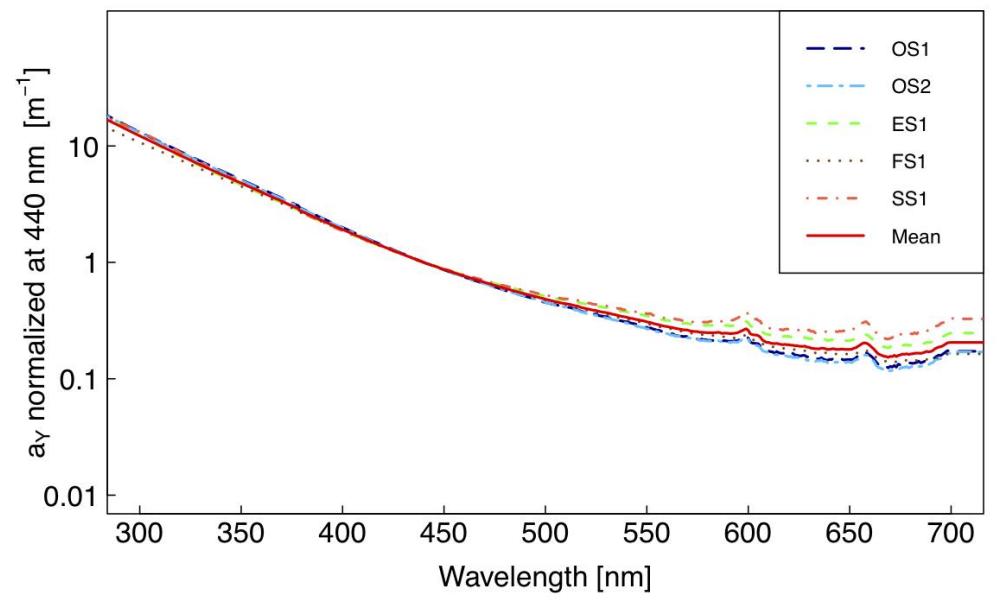

Figure 4. Mean specific absorption coefficient $a_{Y}{ }^{*}(\lambda)$ of each sampling site normalized at $\lambda_{0}=440 \mathrm{~nm}$. The red line represents the mean specific absorption coefficient $a_{Y, O S} *(\lambda)$ of all CDOM measurements $(N=60)$. 


\subsection{Validation of fit results}

The results of laboratory analysis of the water samples, which were presented in section 4.1, are used to validate the corresponding parameters obtained by inverse modeling of downwelling irradiance measurements. Fit results from $E_{d}$ measurements performed at a water depth of $1 \mathrm{~m}$ or less showed strong fluctuation of the fitted $a_{Y}(440)$. Therefore only fit results from $1.5 \mathrm{~m}$ water depth or more are considered, leaving $N=24$ samples for the comparison.

In order to account for possible sensitivity of the fit results on initialization, data analysis was conducted for different initial values for $Y$ and $C_{i}$, while the initial values for $X, f_{d d}, f_{d s}, \alpha, \beta, H_{o z}, W V$ and $z$ were not changed. The influence of the specific absorption coefficient of $\mathrm{CDOM}, a_{Y}^{*}(\lambda)$, was investigated by using different $S$ values in the exponential approximation, treating $S$ as fit parameter, and using the measured spectrum $a_{Y, O S}{ }^{*}(\lambda)$ from Figure 4 instead of the exponential function. In Table 2 the fit results of the different settings are summarized.

Table 2. Correspondence between $a_{Y}(440)$ obtained from inverse modeling of $E_{d}$ measurements and laboratory analysis of water samples. The columns represent different settings of the inversion algorithm. In the standard setting, CDOM concentration was initialized by $Y=0.5 \mathrm{~m}^{-1}$, the phytoplankton concentrations by $C_{i}=(1,0,0,0) \mathrm{mg} \mathrm{m}^{-3}(i=0,3,4,5)$, and $a_{Y}^{*}(\lambda)$ was calculated as $\exp [-S(\lambda-440)]$ with constant $S=0.0140 \mathrm{~nm}^{-1}$.

\begin{tabular}{|c|c|c|c|c|c|c|c|c|c|c|c|c|}
\hline \multirow{3}{*}{ Changed fit parameter } & \multicolumn{12}{|c|}{ Different settings } \\
\hline & \multirow[b]{2}{*}{$0.5^{\prime}$} & \multicolumn{3}{|c|}{$Y$ initial value $\left[\mathrm{m}^{-1}\right]$} & \multirow[b]{2}{*}{10} & \multirow[b]{2}{*}{$0.014^{\prime}$} & \multicolumn{3}{|c|}{$S$ set value $\left[\mathrm{nm}^{-1}\right]$} & \multirow[b]{2}{*}{$a_{Y O S} *$} & \multicolumn{2}{|c|}{$C_{i}$ classes } \\
\hline & & 0.002 & 1 & 5 & & & 0.004 & 0.025 & fitted & & $C[0]^{\prime}$ & $C[3,4,5]$ \\
\hline $\mathrm{N}$ & 24 & 24 & 24 & 24 & 24 & 24 & 24 & 24 & 24 & 24 & 24 & 24 \\
\hline coefficient of determination & 0.92 & 0.00 & 0.90 & 0.90 & 0.00 & 0.92 & 0.64 & 0.80 & 0.91 & 0.87 & 0.92 & 0.93 \\
\hline slope & 0.80 & -0.02 & 0.81 & 0.80 & 0.11 & 0.80 & 0.49 & 1.38 & 0.76 & 0.91 & 0.80 & 0.74 \\
\hline $\mathrm{y}$-intercept $\left[\mathrm{m}^{-1}\right]$ & 0.08 & 0.20 & 0.09 & 0.08 & 1.27 & 0.08 & 0.30 & 0.34 & 0.13 & 0.01 & 0.08 & 0.12 \\
\hline $\begin{array}{c}\text { standard deviation } \\
\text { of fitted } a_{Y}(440) \quad\left[\mathrm{m}^{-1}\right]\end{array}$ & 0.06 & 0.14 & 0.05 & 0.07 & 1.29 & 0.06 & 0.11 & 0.13 & 0.06 & 0.06 & 0.06 & 0.06 \\
\hline
\end{tabular}

The standard setting yields a high coefficient of determination of $\mathrm{R}^{2}=0.92$, a slope of 0.80 , a y-intercept of $0.08 \mathrm{~m}^{-1}$, and a standard deviation of $0.06 \mathrm{~m}^{-1}$ (Figure 5a). Changing $Y$ initial values from the standard value of $0.5 \mathrm{~m}^{-1}$ to the extreme values of $0.002 \mathrm{~m}^{-1}$ and $10 \mathrm{~m}^{-1}$ destroys the correlation. $Y$ initial values of $1 \mathrm{~m}^{-1}$ and $5 \mathrm{~m}^{-1}$ affect the fit results only slightly, i.e. the inversion algorithm is quite robust concerning $Y$ initialization and tolerates deviations by an order of magnitude from the real concentration. Unrealistic slope values decrease the correlation and increase the standard deviation of the fit results. Fitting the slope $S$ in addition to the other fit parameters results in no better correlation. The best regression results are obtained by taking the mean specific absorption spectrum of the Osterseen Lake District, $a_{Y, O S} *(\lambda)$ (Figure $5 \mathrm{c}$ ). The slope of the regression line is closer to 1 than for any other setting $(0.91)$, and the $y$-intercept is very close to zero $\left(0.01 \mathrm{~m}^{-1}\right)$. Treating the three typical phytoplankton classes separately declines the regression parameters, indicating that no further differentiation between the phytoplankton classes can be performed using the applied settings of the inversion algorithm.

The correlation result from the standard setting and using $a_{Y, O S} *(\lambda)$ is illustrated in Figure $5 \mathrm{a}$ and $5 \mathrm{c}$. Different sampling depths are marked in different colors. Additionally the dependency of the standard deviation of the fitted $a_{Y}(440)$ values on sensor depth is shown in Figure $5 \mathrm{~b}$ and $5 \mathrm{~d}$. Gege ${ }^{14}$ already observed that a path length of 1 to $1.5 \mathrm{~m}$ is required to derive reliably absorption from $E_{d}$ measurements. This result can be confirmed for the CDOM retrieval of this study.

A similar analysis was made for $S$. Fitted $S$ values and $S$ values obtained from water samples are only weakly correlated $\left(\mathrm{R}^{2}=0.23\right.$, slope $=0.143$, y-intercept $\left.=0.01 \mathrm{~nm}^{-1}\right)$, i.e. $S$ cannot be determined reliably by inverse modeling of $E_{d}$ measurements. 

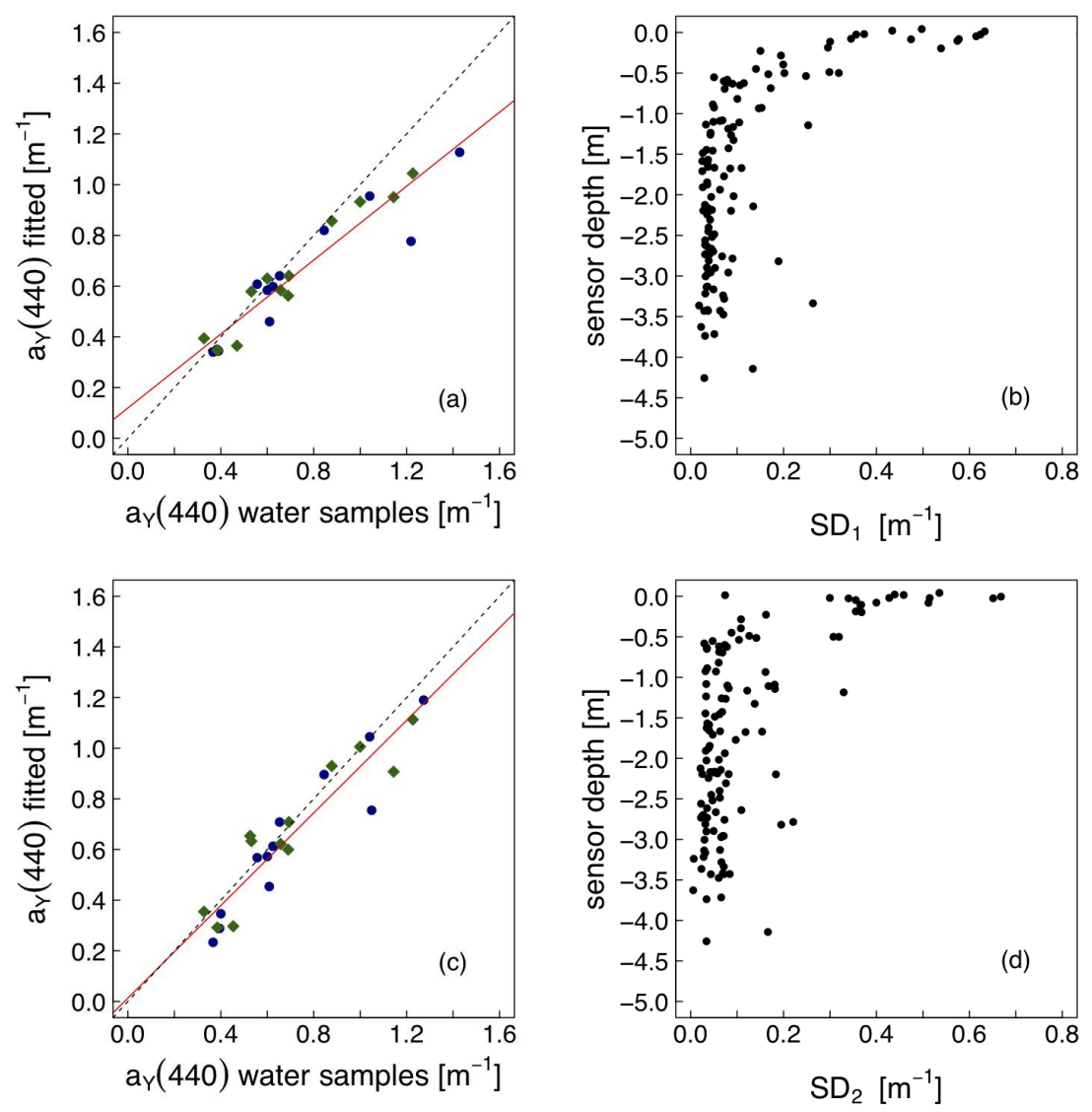

Figure 5. Illustration of the two best fit results. (a) $a_{Y}(440)$ determined using the standard setting.(b) The calculated standard deviation of the fitted CDOM concentrations as function of sensor depth. (c) $a_{Y}(440)$ determined using $a_{Y, O S} *(\lambda)$ and (d) the corresponding standard deviation as function of sensor depth. Different colors and symbols represent the two sampling depths, $2 \mathrm{~m}$ (blue points) and Secchi disk depth (green rhombs).

\section{CONCLUSION}

The potential of a new analytical model for downwelling irradiance in water, which can cope with the large and unpredictable fluctuations of the underwater light field, for estimating CDOM was analyzed in this study. The accuracy of the derived parameters was determined by comparison with independent laboratory measurements of water samples, which were acquired simultaneously to the underwater spectral measurements. The campaigns were performed in different lakes of the Osterseen Lake District in summer 2012. Realistic concentrations were obtained for sampling depths above $1.5 \mathrm{~m}$ for all sampling sites. The accuracy depends on the knowledge of the spectral shape of CDOM absorption, represented by the spectrum $a_{Y}{ }^{*}(\lambda)$. The standard exponential approximation with the spectral slope $S=$ $0.0140 \mathrm{~nm}^{-1}$ provided already good results $\left(\mathrm{R}^{2}=0.92\right)$ because this $S$ value is close to the average of $0.0145 \mathrm{~nm}^{-1}$ of the sampling lakes. Replacing the exponential $a_{Y}{ }^{*}(\lambda)$ model by the average spectrum $a_{Y, O S}{ }^{*}(\lambda)$ for the Osterseen Lake District clearly improves the fit results. The spectrum $a_{Y, O S}{ }^{*}(\lambda)$, which has been determined in this study, differs slightly from an exponential function. Interestingly, changing the phytoplankton classes did not improve the fit results. Hence the default spectrum of phytoplankton absorption in WASI, which is a weighted sum of five phytoplankton spectra from Lake Constance, can also be used for the freshwater lakes studied here. The spectral slope $S$ could not be determined accurately by inverse modeling of the irradiance spectra, but as correlation with the laboratory results was significant, it may be worth to spend further investigation on this matter in future. Overall this new model of downwelling irradiance can be used as an alternative to laboratory analysis of water samples to determine CDOM concentration. 


\section{ACKNOWLDGMENT}

This study was realized at the Limnologische Station Iffeldorf (LSI), Bavaria Germany. Thanks to the scientific staff of the LSI for helping to analyze CDOM data, which was used in this work.

\section{REFERENCES}

[1] Belzile, C., Gibson, J. A., and Vincent, W. F., "Colored dissolved organic matter and dissolved organic carbon exclusion from lake ice: Implications for irradiance transmission and carbon cycling," Limnol. Oceanogr. 47(5), 1283-1293 (2002).

[2] Röttgers, R., and Doerffer, R., "Measurements of optical absorption by chromophoric dissolved organic matter using a point-source integrating-cavity absorption meter," Limnol. Oceanogr. Methods 5, 126-135 (2007).

[3] Dekker, A., Vos, R., and Peters, S., "Comparison of remote sensing data, model results and in situ data for total suspended matter (TSM) in the southern Frisian lakes," Sci. Total. Environ. 268(1), 197-214 (2001).

[4] Jones, R. I., "Phytoplankton, primary production and nutrient cycling," Aquatic Humic Substances, Springer-Verlag, Berlin, 145-175 (1998).

[5] Pienitz, R., and Vincent, W. F., "Effect of climate change relative to ozone depletion on UV exposure in subarctic lakes," Nature 404(6777), 484-487 (2000).

[6] Arrigo, K. R., and Brown, C. W., "Impact of chromophoric dissolved organic matter on UV inhibition of primary productivity in the sea," Mar. Ecol. Prog. Ser. 140(1), 207-216 (1996).

[7] Tranvik, L. J., "Bacterioplankton growth on fractions of dissolved organic carbon of different molecular weights from humic and clear waters," Appl. Environ. Microbiol. 56(6), 16721677 (1990).

[8] Williamson, C. E., Morris, D. P., Pace, M. L., and Olson, O. G., "Dissolved organic carbon and nutrients as regulators of lake ecosystems: Resurrection of a more integrated paradigm," Limnol. Oceanogr. 44(3), 795-803 (1999).

[9] Freeman, C., Fenner, N., Ostle, N., Kang, H., Dowrick, D., Reynolds, B., Lock, M., Sleep, D., Hughes, S., and Hudson, J., "Export of dissolved organic carbon from peatlands under elevated carbon dioxide levels," Nature 430(6996), 195-198 (2004).

[10] Tranvik, L., and Jansson, M., "Climate change (communication arising): terrestrial export of organic carbon," Nature 415(6874), 861-862 (2002).

[11] Kutser, T., Pierson, D. C., Kallio, K. Y., Reinart, A., and Sobek, S., "Mapping lake CDOM by satellite remote sensing," Remote Sens. Environ. 94(4), 535-540 (2005).

[12] Hakvoort, H., de Haan, J., Jordans, R., Vos, R., Peters, S., and Rijkeboer, M., “Towards operational airborne remote sensing of water quality in the netherlands "International Archieves of Photogrammetry and Remote Sensing 33(B7/2; PART 7), 489-495 (2000).

[13] Groetsch, P., and Gege, P., "Determination of sensor depth from downwelling irradiance measurements," Proc. IGARSS (2012).

[14] Gege, P., "Estimation of phytoplankton concentration from downwelling irradiance measurements in water," Isr. J. Plant. Sci. 60(1-2), 193-207 (2012).

[15] Gege, P., and Pinnel, N., "Sources of variance of downwelling irradiance in water," Appl. Opt. 50(15), 2192-2203 (2011).

[16] Walker, R. E., [Marine light field statistics] Wiley New York(1994). 
[17] Zaneveld, J. R. V., Boss, E., and Barnard, A., "Influence of surface waves on measured and modeled irradiance profiles," Appl. Opt. 40(9), 1442-1449 (2001).

[18] Dera, J., Sagan, S., and Stramski, D., "Focusing of sunlight by sea surface waves: new results from the Black Sea," Oceanologia 34, (1993).

[19] Hofmann H., Lorke A., and F., P., "Wave induced variability of the underwater light climate in the littoral zone," Verhandlungen des Internationalen Verein Limnologie 30, 627-632 (2008).

[20] Hieronymi, M., and Macke, A., "On the influence of wind and waves on underwater irradiance fluctuations," Ocean Sci. 8(4), 455-471 (2012).

[21] Gege, P., "Analytic model for the direct and diffuse components of downwelling spectral irradiance in water," Appl. Opt. 51(9), 1407-1419 (2012).

[22] Gege, P., "A model of underwater spectral irradiance accounting for wave focusing," AIP Conference Proceedings 1531, 931-934 (2013).

[23] Gregg, W. W., and Carder, K. L., "A simple spectral solar irradiance model for cloudless maritime atmospheres," Limnol. Oceanogr., 1657-1675 (1990).

[24] Lee, Z.-P., Du, K.-P., and Arnone, R., "A model for the diffuse attenuation coefficient of downwelling irradiance,” J. Geophys. Res. 110(C2), C02016 (2005).

[25] Melzer, A., "Makrophytische Wasserpflanzen als Indikatoren des Gewässerzustandes oberbayrischer Seen,” Dissertationes Botanicae, J. Cramer, (1976).

[26] Gege, P., "Improved method for measuring gelbstoff absorption spectra," Ocean Optics Conference XVII, 25-29 (2004).

[27] Rößler, S., Wolf, P., Schneider, T., and Melzer, A., "Identifizierung und Überwachung invasiver Wasserpflanzen mit RapidEye," RapidEye Science Archive (RESA) - Vom Algorithmus zum Produkt, GITO Verlag, Berlin, 73-89 (2012). 